\title{
Future Summer Drying in the U.S. Corn Belt and the Role of Midlatitude Storm Tracks
}

\author{
Mingfang Ting, ${ }^{\mathrm{a}}$ Richard Seager, ${ }^{\mathrm{a}}$ Cuinua Li,${ }^{\mathrm{a}}$ Haibo Liu, ${ }^{\mathrm{a}}$ AND NaOmi Henderson ${ }^{\mathrm{a}}$ \\ ${ }^{a}$ Lamont-Doherty Earth Observatory, Columbia University, New York, New York
}

(Manuscript received 28 December 2020, in final form 14 July 2021)

\begin{abstract}
During the summer, the midwestern United States, which covers the main U.S. corn belt, has a net loss of surface water as evapotranspiration exceeds precipitation. The net moisture gain into the atmosphere is transported out of the region to the northern high latitudes through transient eddy moisture fluxes. How this process may change in the future is not entirely clear despite the fact that the corn-belt region is responsible for a large portion of the global supply of corn and soybeans. We find that increased $\mathrm{CO}_{2}$ and the associated warming increase evapotranspiration while precipitation reduces in the region, leading to further reduction in precipitation minus evaporation in the future. At the same time, the poleward transient moisture flux increases, leading to enhanced atmospheric moisture export from the corn-belt region. However, storm-track intensity is generally weakened in the summer because of a reduced north-south temperature gradient associated with amplified warming in the midlatitudes. The intensified transient eddy moisture transport as the storm track weakens can be reconciled by the stronger mean moisture gradient in the future. This is found to be caused by the climatological low-level jet transporting more moisture into the Great Plains region as a result of the thermodynamic mechanism under warmer conditions. Our results, for the first time, show that in the future the U.S. Midwest corn belt will experience more hydrological stress due to intensified transient eddy moisture export, leading to drier soils in the region.

SIGNIFICANCE STATEMENT: The U.S. corn belt has dominated corn production in the United States since the 1850 s, accounting for more than one-third of the global supply of corn, and is the world's largest source of soybeans. Yet how the region's hydroclimate responds to future climate change is still unclear. Here we found that increased $\mathrm{CO}_{2}$ and the associated warming increase evapotranspiration that takes more moisture out of the soil, thus leading to a drying effect. At the same time, the storms are becoming weaker and are shifted northward, leading to less precipitation in the corn-belt region. The excess moisture from the evapotranspiration is transported out of the corn-belt region by eddies. These processes together contribute to the corn belt's increased hydrological stress in the future.
\end{abstract}

KEYWORDS: Drought; Precipitation; Storm tracks; Moisture/moisture budget

\section{Introduction}

The U.S. corn belt, which stretches from western Ohio to eastern Nebraska and from $35^{\circ} \mathrm{N}$ latitude all the way to the U.S.-Canada border (Green et al. 2018), accounts for the majority of the corn and soy bean production in the United States and half of the global supply of corn and soybeans (Fig. 1; USDA-NASS 2018). Yet it is not entirely clear how future climate change may impact the hydroclimate conditions in this region.

CMIP5 models tend to show a future drying and warming in the central U.S. Great Plains region (e.g., Maloney et al. 2014; Seager et al. 2014). Yet climate models also show a generally warm and dry bias in the region relative to observations (Klein et al. 2006; Mueller and Seneviratne 2014; Lin et al. 2017). The warm and dry bias is believed to be caused by land-atmosphere feedback and soil moisture deficit that leads to surface

¿ Denotes content that is immediately available upon publication as open access.

Corresponding author: Mingfang Ting, ting@ldeo.columbia.edu drying (Klein et al. 2006; Lin et al. 2017). This raises the question of how reliable future projections are in this region. The importance of future hydroclimate change in the corn belt is obvious, as the region provides half of the world's corn and soybean supply. Is the model projection completely unreliable? How do we know if the model projections are physically based? These are the questions that motivate this study.

Summer reductions in soil moisture in midlatitudes have long been recognized as a feature of global climate model simulations of the effects of rising greenhouse gases (e.g., Manabe et al. 1981; Wilson and Mitchell 1987). This remains a widespread feature in CMIP5 models even as models showing increases in leaf area index and net primary productivity, which are sensitive to both hydrological changes and the biophysical impacts of rising $\mathrm{CO}_{2}$ (Mankin et al. 2017). Mankin et al. (2017) refer to this as the "drying but greening" model response. Much of the discussion of these model results centers on the exchange of moisture between the land surface and the atmosphere and follows from the fundamental fact that the atmosphere can hold more moisture as it warms. On its own, atmospheric warming increases the potential evapotranspiration and will act as a tendency to reduce soil moisture 

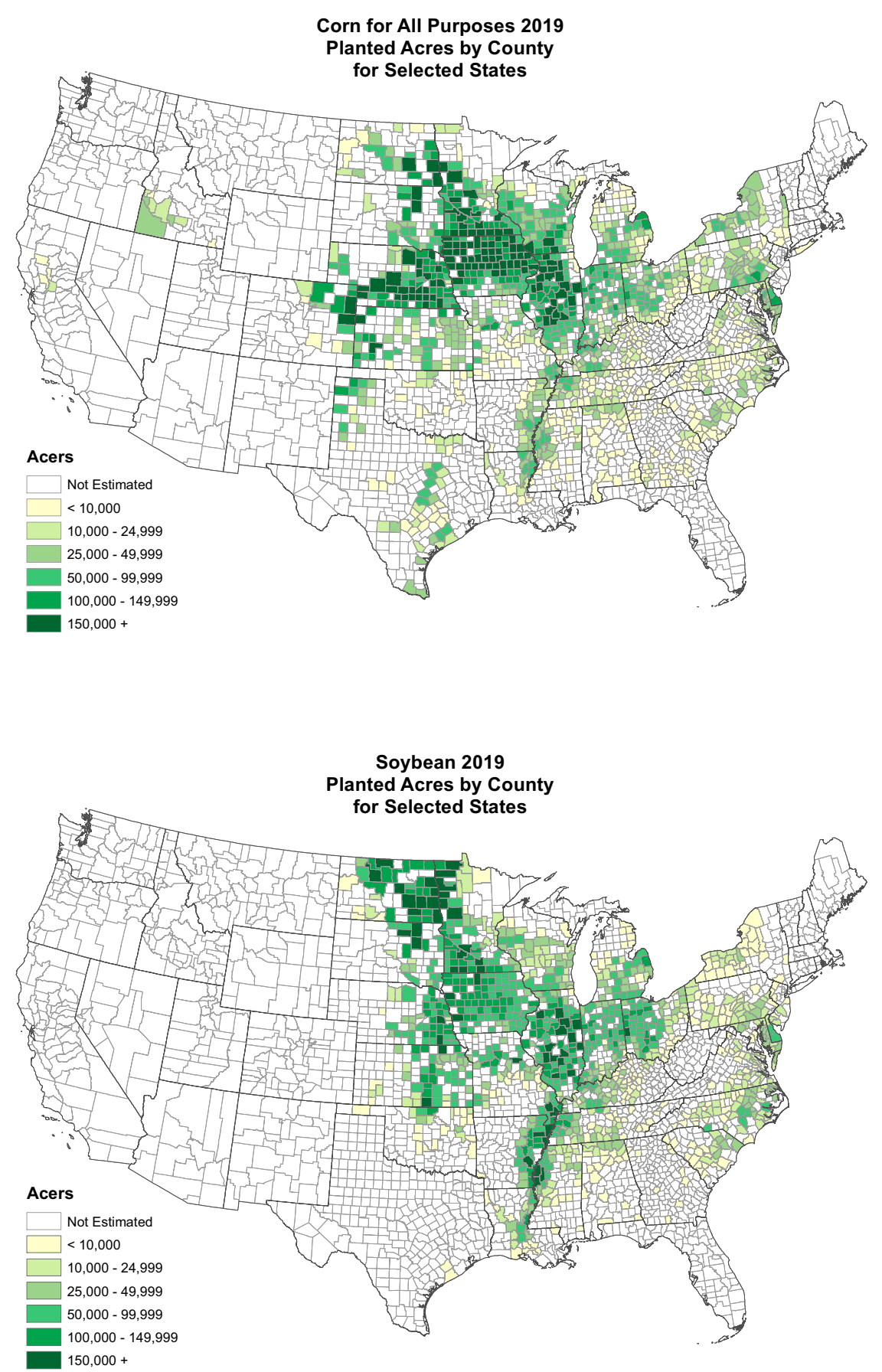

FIG. 1. Planted acres of (top) corn and (bottom) soybeans by county in 2019. The data are taken from the U.S. Department of Agriculture National Agricultural Statistics Service Quick Stats (https://quickstats.nass.usda.gov/\#5BB22A04-2119-3B10-A2AECFD0858A3AC2).

(e.g., Sherwood and Fu 2014; Fu and Feng 2014). However, the relevance of potential evapotranspiration has been questioned given the control that plants exert on actual evapotranspiration (e.g., Milly and Dunne 2016; Lemordant et al. 2018). Further, rising $\mathrm{CO}_{2}$ increases the water use efficiency of photosynthesis such that plants might transpire less water for the same carbon uptake (e.g., Swann et al. 2016). However, soil moisture declines are widespread in CMIP5 models that attempt to simulate the biophysical responses of plants to warming temperatures and $\mathrm{CO}_{2}$ increases (Mankin et al. 2017, 2018, 
2019), creating a continuity of simulated summer continental drying responses across multiple generations of climate models. Further, Cook et al. (2015) have shown that summer soil moisture drying in the continental United States in CMIP5 models tracks that deduced from offline Palmer drought severity index calculations that are definitely strongly influenced by increasing atmospheric evaporative demand.

However, rising evaporative demand cannot be a satisfactory explanation for soil moisture drying. While there is evidence of an increasing recycling ratio (the fraction of precipitation over a region that originates as evaporation from the same region) over the corn-belt region during the summer season in recent years (Dirmeyer and Brubaker 2006), if the moisture removed from the soil to the atmosphere were to return as precipitation then there would be no change in precipitation minus evapotranspiration and no soil moisture tendency, assuming runoff does not change substantially, which is shown to be true in the models we looked at. Instead, for higher evaporative demand to actually dry soils the moisture in the atmosphere must be transported elsewhere. That is, soil moisture drying must go along with anomalous atmospheric moisture divergence. By implication, it therefore must also go along with enhanced atmospheric moisture convergence, and a tendency to wet soils if over land, elsewhere. This coupling between soil moisture changes and atmospheric moisture transports was recognized by Rind (1988) but is not addressed in much of the recent literature on changes in continental ecohydrology.

In the current paper we attempt to understand the physical mechanisms that allow enhanced moisture divergence, and an increase in evapotranspiration minus precipitation, to drive soil moisture drying in the U.S. corn belt in summer. This presumably occurs via a perturbation to the climatological mean moisture budget. Seager et al. (2014) used atmospheric reanalysis to show that in the summer the mean flow and evapotranspiration excess over precipitation both provide moisture to the atmosphere above the central United States and transient eddies diverge the moisture away. The work here will focus on (i) how these processes change such that the atmosphere performs the moisture export that allows the surface drying and (ii) the relative roles of changes in atmospheric circulation and humidity, and of the mean circulation and transient eddies, in accomplishing this moisture export.

\section{Data and methods}

We used the same 22 CMIP5 models (Table 1) as in Seager et al. (2014) and Ting et al. (2018) in this study. These models provide 6-hourly data for calculating transient eddy moisture fluxes necessary for the analysis. These 22 models were selected also because they provide both the historical simulations (20thC) and future projections with the representative concentration pathway 8.5 (RCP8.5). We use 1979-2005 as the present-day base period, and the future changes in hydroclimate and moisture budget are with respect to the reference period. The multimodel ensemble average is generated by regridding all model data to a common $1^{\circ} \times 1^{\circ}$ latitude-longitude grid using a bilinear interpolation method.

For validating the CMIP5 simulations, we used the European Center for Medium-Range Weather Forecasts (ECMWF) interim reanalysis (ERA-Interim, herein ERA-I; Dee et al. 2011) for the same period, 1979-2005, for direct comparisons. The 6-hourly ERA-I data were used for calculating transient eddy statistics used in this study and monthly data for the rest of the analysis. Precipitation data from Global Precipitation Climatology Center (GPCC; Schneider et al. 2014) and the University of East Anglia Climate Research Unit (CRU; Harris et al. 2020) were also used for further validation of the CMIP5 model simulation and the ERA-I reanalysis.

We follow the moisture budget analysis approach used in Seager and Henderson (2013) and Ting et al. (2018) for both the ERA-I and CMIP5 present and future simulations. The column-averaged moisture budget can be expressed in pressure coordinates as

$$
P-E=-\frac{1}{g \rho_{w}} \nabla \cdot \int_{0}^{p_{s}} \mathbf{u} q d p
$$

where $P$ represents precipitation, $E$ is evapotranspiration, $g$ is the gravitational constant, $\rho_{w}$ is water density, $p$ is pressure and $p_{s}$ is its surface value, $q$ is specific humidity, and $\mathbf{u}$ is the horizontal wind vector. Performing a monthly average on both sides of Eq. (1) and separating the right side of the equation into the sum of monthly mean moisture convergence and the submonthly (deviation from the monthly mean) transient eddy moisture convergence, Eq. (1) can be expressed as

$$
\bar{P}-\bar{E}=-\frac{1}{g \rho_{w}} \nabla \cdot \int_{0}^{p_{s}} \bar{u} \bar{q} d p-\frac{1}{g \rho_{w}} \nabla \cdot \int_{0}^{p_{s}} \overline{u^{\prime} q^{\prime}} d p,
$$

where the overbar indicates monthly mean and the prime indicates daily deviation from the monthly mean. We can further separate the first term on the right-hand side of Eq. (2) into three terms, including the mean moisture advection and mass divergence as well as a boundary term related to surface pressure:

$$
\nabla \cdot \int_{0}^{p_{s}} \bar{u} \bar{q} d p=\int_{0}^{p_{s}} \bar{u} \cdot \nabla \bar{q} d p+\int_{0}^{p_{s}} \bar{q} \nabla \cdot \bar{u} d p+\bar{q}_{s} \bar{u}_{s} \cdot \nabla p_{s},
$$

where $\bar{q}_{s}$ and $\bar{u}_{s}$ represent the surface specific humidity and vector horizontal wind, respectively. The boundary term is usually small except in regions where there are mountains with large surface pressure gradients.

The change in moisture budget over two different periods for Eq. (2) can be written as

$$
\delta(\overline{\bar{P}-\bar{E}})=\delta\left(\overline{-\frac{1}{g \rho_{w}} \nabla \cdot \int_{0}^{p_{s}} \bar{u} \bar{q} d p}\right)+\delta\left(\overline{-\frac{1}{g \rho_{w}} \nabla \cdot \int_{0}^{p_{s}} \overline{u^{\prime} q^{\prime}} d p}\right),
$$


TABLE 1. CMIP5 models used in this study, including their originating institutions, horizontal and vertical resolutions, and ensemble sizes [expansions of model names are available online (http://www.ametsoc.org/PubsAcronymList)].

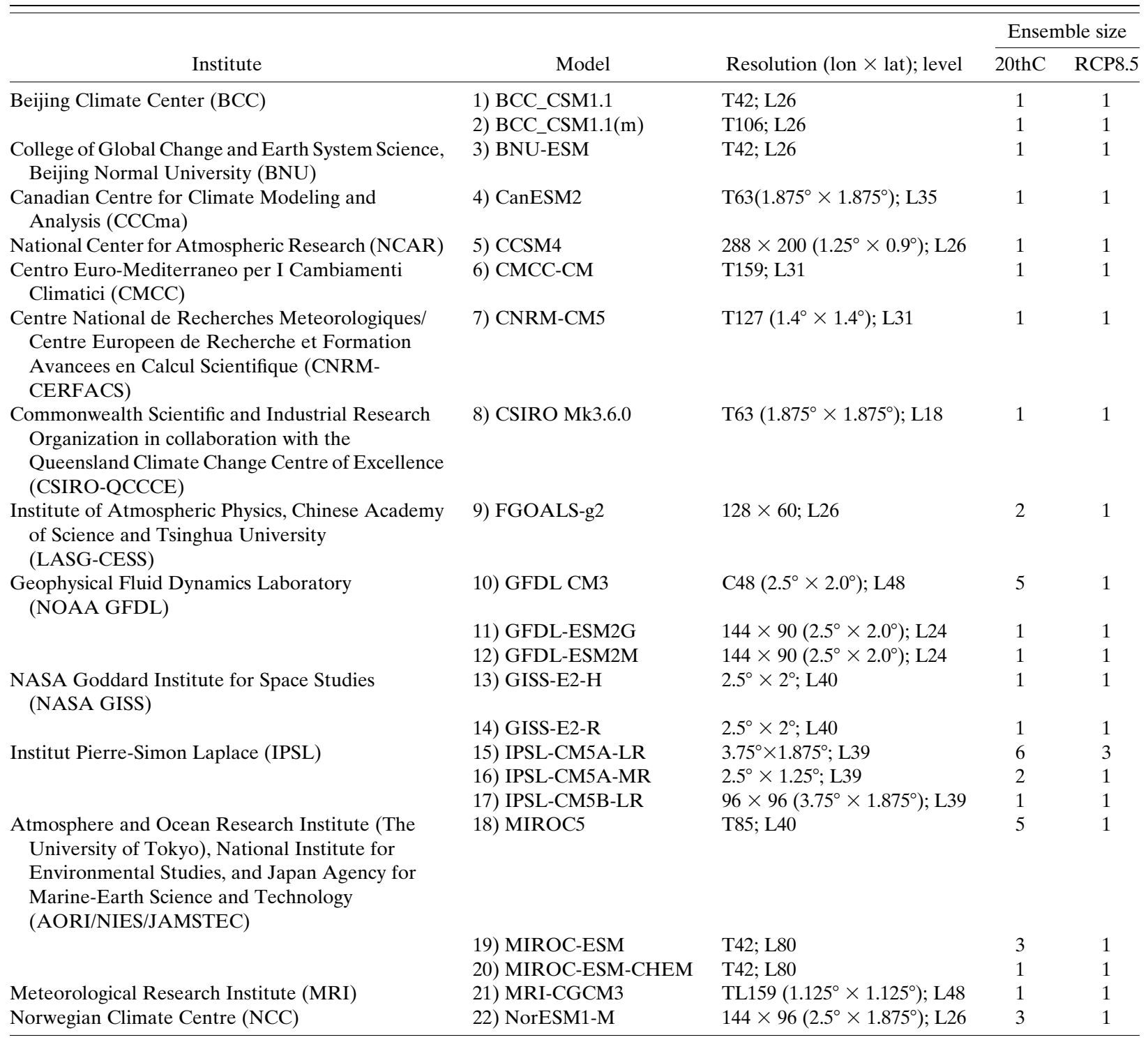

where $\delta$ represents the difference between the two periods, and the long bar represents each period average. The first term on the right-hand side of Eq. (4) can be further separated into two terms representing changes of mean moisture convergence, that due to horizontal wind changes alone [dynamic (DYN)] and that due to changes in specific humidity alone [thermodynamic $(\mathrm{TH})]$ :

$$
\begin{aligned}
& \delta\left(\overline{-\frac{1}{g \rho_{w}} \nabla \cdot \int_{0}^{p_{s}} \bar{u} \bar{q} d p}\right) \cong \frac{1}{g \rho_{w}} \overline{\nabla \cdot \int_{0}^{p_{s}} \delta \overline{u q_{p}} d p} \\
& +\frac{1}{g \rho_{w}} \overline{\nabla \cdot \int_{0}^{p_{s}}\left(\bar{u}_{p}\right) \delta \bar{q} d p}=\delta \overline{\overline{\mathrm{DYN}}}+\delta \overline{\overline{\mathrm{TH}}}
\end{aligned}
$$

where $\delta$ represents the difference between the future period and the present-day base period (1979-2005) (i.e., $\delta \bar{u}=\bar{u}_{f}-\bar{u}_{p}$ and $\delta \bar{q}=\bar{q}_{f}-\bar{q}_{p}$ ) and subscripts $f$ and $p$ represent future and present-day values. These various decompositions will be used in the rest of the paper to disentangle the role of the various physical processes in contributing to changes in future hydroclimate in the corn-belt region. For spatial averaging we define the corn-belt regions as $104^{\circ}-81^{\circ} \mathrm{W}, 37^{\circ}-49^{\circ} \mathrm{N}$ (the outlined area in Fig. 2).

\section{Summer mean moisture budget in the U.S. corn belt}

To understand how hydroclimate may change in the future, it is necessary to examine in detail how the region maintains its moisture budget in the summer (i.e., what are the dominant moisture sources and sinks, and how well climate models represent these processes). We first examine how well CMIP5 
a) CMIP5 MMM

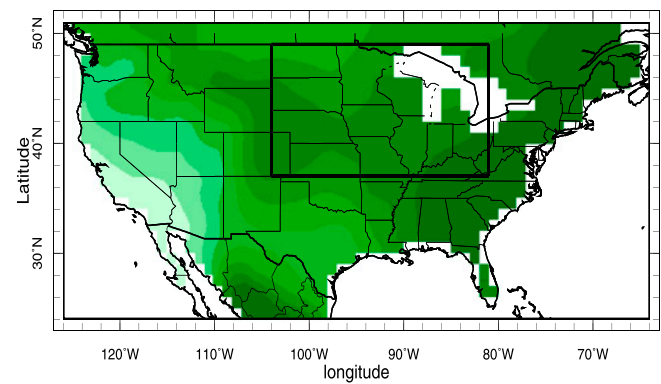

c) GPCC

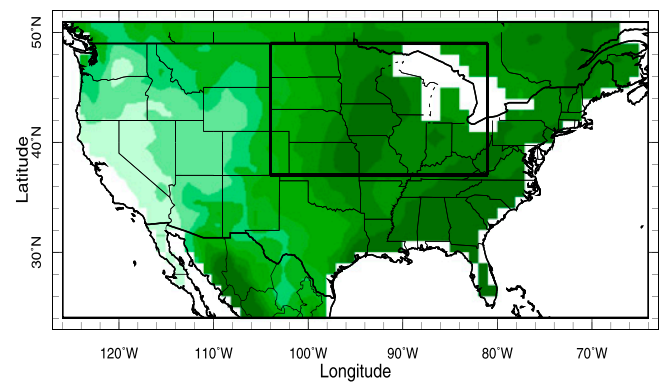

e) CMIP5 MMM - GPCC

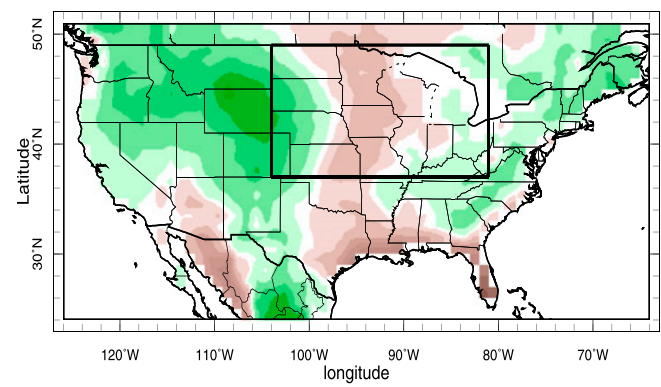

b) ERAInt

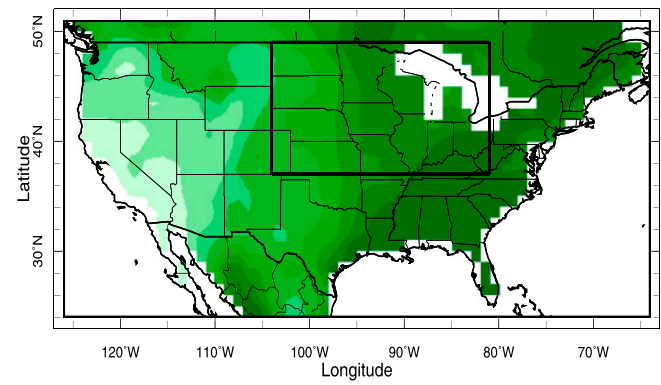

d) $\mathrm{CRU}$

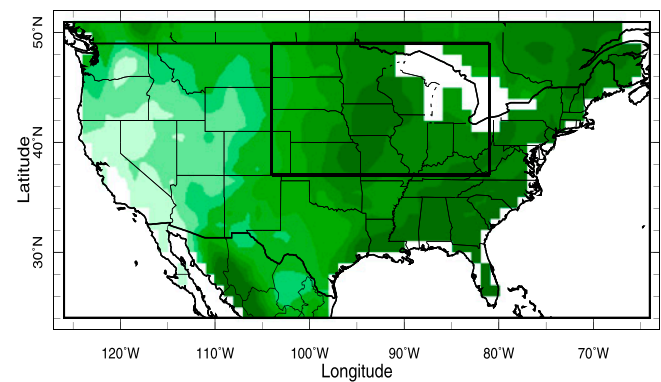

f) CMIP5 MMM - ERAInt

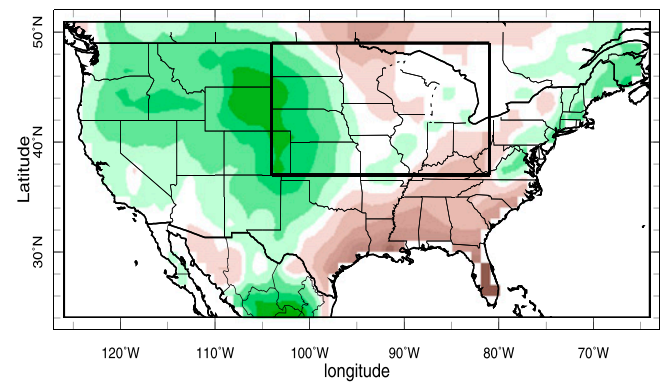

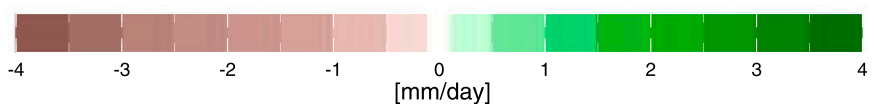

FIG. 2. Climatological mean (1979-2005) summer (JJA) precipitation ( $\mathrm{mm} \mathrm{day}^{-1}$ ) for (a) the CMIP5 multimodel mean (MMM), (b) ERA-I, (c) GPCC, and (d) CRU gridded precipitation. The differences (e) between CMIP5 MMM and GPCC and (f) between CMIP5 MMM and ERA-I are also shown. The black rectangle outlines the U.S. corn-belt region $\left(104^{\circ}-81^{\circ} \mathrm{W}, 37^{\circ}-49^{\circ} \mathrm{N}\right)$.

models simulate the summer mean precipitation in the United States and the seasonal cycle in the corn-belt region in Figs. 2 and 3. Figure 2 illustrates the June, July, and August average precipitation for the CMIP5 multimodel mean (MMM), ERA-I reanalysis, and two gridded observational datasets, the GPCC and CRU for the common period 1979 to 2005. Also shown are the differences between CMIP5 MMM and GPCC, and between MMM and ERA-I.

Figure 2 shows clearly that there is a climatological summer maximum precipitation in the U.S. corn-belt region that provides the necessary rainfall needed for corn and soybean growth. This feature is very consistent across the two observational datasets and slightly weaker in the ERA-I reanalysis. ${ }^{1}$ But the same feature is somewhat distorted in the CMIP5 MMM, with a more widespread precipitation maximum toward the west than in observations. As a result, the difference between CMIP5 MMM and GPCC shows a dipole pattern with the models having excess precipitation west of the 100th

\footnotetext{
${ }^{1}$ We compared the ERA5 precipitation for the corn-belt region and noticed very little difference between ERA-I and ERA5.
} 

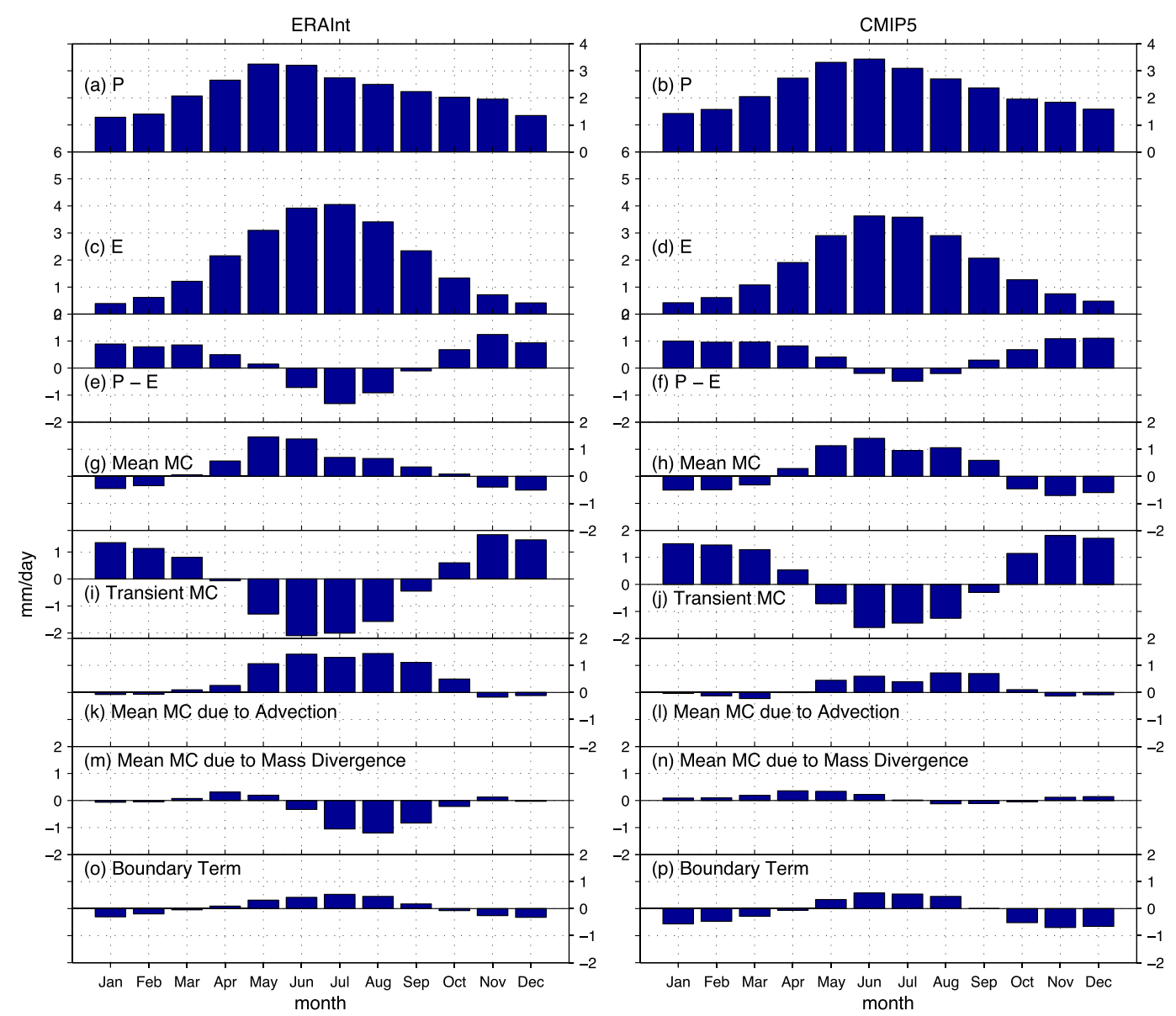

FIG. 3. Seasonal cycle of (a),(b) precipitation; (c),(d) evapotranspiration; (e),(f) precipitation minus evapotranspiration; (g), (h) mean and (i),(j) transient moisture flux convergences; mean moisture convergences due to $(\mathrm{k}),(\mathrm{l})$ advection and $(\mathrm{m}),(\mathrm{n})$ mass divergence; and (o),(p) a residual term, averaged over the corn-belt region outlined in Fig. 2 for (left) ERA-I and (right) CMIP5 multimodel mean.

meridian and drier condition at the center of the corn belt. ${ }^{2}$ These biases have been recognized in several previous studies although the reasons for the biases are not discussed in detail (Sheffield et al. 2013; Lin et al. 2017; Seager et al. 2018). Yet the question of how these biases may impact future projections of the region remains unclear. We address the question from a slightly different angle in this study: how well are models simulating the precipitation processes in the region in terms of the moisture budget and the sources and sinks of moisture? If models can realistically represent the moisture sources and sinks, then it is meaningful to examine how these processes may change in the future. This physics-based approach will provide a more meaningful answer to the purely statistical approach to the model bias and its correction as in

\footnotetext{
${ }^{2}$ We have looked at the CMIP6 MMM precipitation bias as in Fig. 2e and found a slightly reduced wet bias to the west but an even larger dry bias in the corn-belt region relative to CMIP5 MMM, indicating no apparent improvement in the corn-belt precipitation bias from CMIP5 to CMIP6.
}

Lin et al. (2017) and lend more confidence in the future model projections.

Figure 3 examines the seasonal cycle of the U.S. corn-belt region's moisture budget terms in both the ERA-I reanalysis and CMIP5 MMM. The regional averaged $P$ and $E$ in both ERA-I and CMIP5 MMM show similar seasonal cycles with a single peak in the summer months. The net surface water budget, $P-E$, nonetheless shows an excess in winter and a slight deficit in summer due to strong evapotranspiration. Hence, precipitation that falls in winter is stored and sustains evapotranspiration in the following summer. The summer surface water balance is achieved in the atmosphere through the balance between mean and transient eddy moisture convergences, with the mean flow advecting moisture into the region and transient eddies moving moisture out of the region. At first glance, this may seem counterintuitive since transient weather systems are usually the ones that lead to summer precipitation, yet the transient eddies also act as a moisture sink through moisture divergence. This can be reconciled as follows. In the corn-belt region, the atmospheric moisture sources are from evapotranspiration and mean moisture advection from the 
south through the Great Plains low-level jet (e.g., Ting and Wang 2006; Weaver and Nigam 2008). The moisture sinks are through precipitation and transient eddies acting diffusively to move moisture northward down the mean moisture gradient. Since precipitation is also tightly associated with storm-track eddies through frontal and convective precipitation, the transient eddies, or storm tracks, play the dual role of causing precipitation and moving moisture out of the region through eddy diffusion. Thus, a strengthening of the storm tracks in the summer could both increase precipitation and enhance moisture fluxes out of the corn-belt region if evapotranspiration could increase sufficiently to balance. Conversely, a weakening of the storm tracks in the summer could both decrease precipitation and reduce moisture fluxes out of the corn-belt region if evapotranspiration could decrease sufficiently to balance. A schematic summarizing the climatological moisture sources and sinks and the physical processes associated with them, to which we will return, is shown in Fig. 8a, described in more detail later. The remaining question is, How would these processes change in the future? Could the storm tracks change in a way that would alter the moisture budget and lead to hydroclimate change in the corn-belt region? While CMIP5 models slightly underestimate the magnitude of the mean and transient moisture convergences (Fig. 3), the moisture sources and sinks as represented in the ERA-I reanalysis hold up well in CMIP5 models, suggesting that CMIP5 models are able to capture the observed processes as represented in ERA-I reanalysis well. The spatial patterns of the different moisture budget terms for the United States are also very similar between ERA-I and CMIP5 models (not shown). The similarity between CMIP5 models and ERA-I in representing the moisture budget processes in the corn-belt region justifies further examination of the future changes in corn-belt hydroclimate using the models.

\section{Future changes in hydroclimate in the U.S. corn belt}

To explore how hydroclimate may change in the future, we show in Fig. 4 changes in the various moisture budget terms between the end of the twenty-first century and the end of the twentieth century based on the CMIP5 MMM using the RCP8.5 future emission scenario. The changes of each term for four different future periods from the near future (2021-40) to the end of the century (2081-99) averaged over the corn-belt region (outlined region in the spatial maps in Fig. 4) are also shown as bar plots. There are significant deficits in surface moisture in terms of $P-E$ throughout the continental United States. For the corn-belt region, the reduction is due to both reduced precipitation (in the southwest corner region) and increased evapotranspiration (northeast corner) consistent with previous studies (e.g., Cook et al. 2015; Mankin et al. 2018, 2019). The area-averaged precipitation and evapotranspiration shown in Figs. $4 \mathrm{~b} 2$ and 4c2 indicate consistent decrease in precipitation and increase in evapotranspiration across the future periods. The increase in evapotranspiration tends to dominate over precipitation decrease in the first three future periods in the corn belt as a whole. Previous studies have shown that an enhanced warming over continents, along with a decrease in relative humidity due to anthropogenic greenhouse forcing, can lead to increases in vapor pressure deficit and robust increases in evapotranspiration over land (e.g., Sherwood and Fu 2014; Fu and Feng 2014). The negative $P-E$ is balanced dominantly by enhanced transient moisture divergence, which is offset slightly by increases in mean moisture convergence. The future increases in mean moisture convergence come from both changes in circulation (dynamic) and moisture content (thermodynamic). The strong reduction in $P-E$ leads to drier soils in the region, as changes in total runoff for the region tend to be negligible (figure not shown). These changes are consistent throughout the future periods, from the near future to the end of this century (shown in the bar plots).

The dominance of the increased transient moisture flux divergence in determining the future drying in this region suggests that changes in transient eddy activity, or in other words, storm-track intensity, may be a key in explaining the future summer drying. Figure 5 shows the change in zonal wind and submonthly transient eddy kinetic energy $\overline{\left(u^{\prime 2}+v^{\prime 2}\right.}$, where primes denote daily deviation from its monthly mean value) from the 22 CMIP5 models (multimodel mean) for both the 1979-2005 climatology and future changes (2075-2100 minus 1979-2005) for the Northern Hemisphere summer season [JuneAugust (JJA)]. It is clear from Fig. 5 that there is a reduction in zonal wind on the south side of the North American/Atlantic jet and on the north side of the Asian/Pacific jet at both upper and lower tropospheric levels. This reduction in jet intensity is generally understood as caused by the reduction in meridional temperature gradient in the lower troposphere due to increased warming in northern midlatitudes. As a result of a weakened tropospheric jet, the storm activity is substantially reduced as well (Figs. 5b,d), leading to a much weaker summer storm track in the future. As shown in Fig. 3, submonthly transient eddies tend to cause moisture divergence in the cornbelt region, so one might expect that a reduced storm track would lead to reduced transient moisture divergence in the future. Yet, Fig. 4 indicates a robust enhancement of the transient eddy moisture divergence in the future when stormtrack intensity is reduced. What are the causes for this seemingly contradictory result?

We explore the perplexing results between storm-track intensity and transient eddy moisture flux in Fig. 6, which illustrates the summer climatological mean and future changes in the North American sector $\left(130^{\circ}-50^{\circ} \mathrm{W}\right)$ zonal mean zonal wind, temperature, specific humidity, the transient meridional wind variance (as a measure of storm-track intensity), and transient heat and moisture fluxes. The zonal mean of these quantities across all longitudes looks similar to the regional zonal mean in Fig. 6. In the greenhouse warming future, while the global mean temperature increases everywhere, it increases more near the northern midlatitudes from $30^{\circ}$ to $60^{\circ} \mathrm{N}$ (Fig. 6c), which decreases the zonal mean temperature gradient south of $40^{\circ} \mathrm{N}$ and increases slightly north of $40^{\circ} \mathrm{N}$. The future warming pattern in zonal mean temperature shown in Fig. $6 c$ is consistent with observed tropospheric temperature trends since 1979 (Fu et al. 2006; Santer et al. 2018). The warming pattern in Fig. 6c subsequently leads to reduced zonal mean zonal wind in the troposphere at $\sim 40^{\circ} \mathrm{N}$ and enhanced zonal wind at $60^{\circ} \mathrm{N}$, leading to the northward shift of 
CMIP5 Moisture Budget Terms for JJA, (2075-2099) - (1979-2005)

a1) P-E

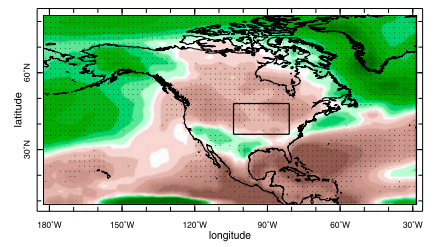

c1) $\mathrm{E}$

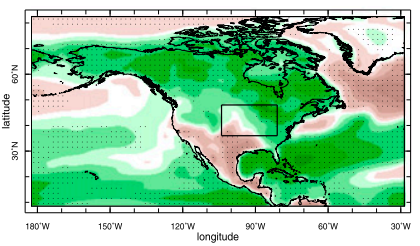

e1) Transient MC

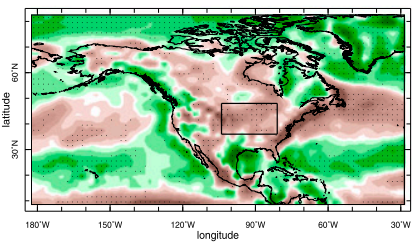

g1) $\mathrm{TH}$

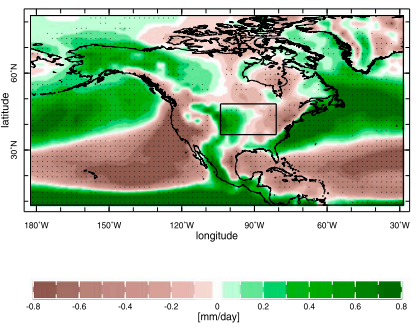

b1) $\mathrm{P}$

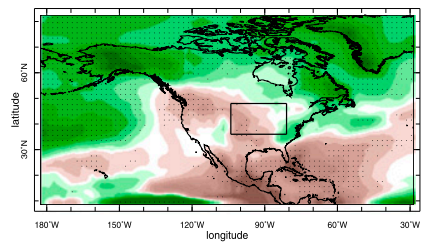

d1) Mean MC

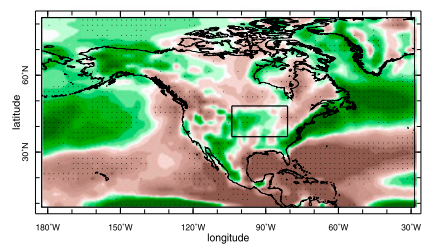

f1) DYN

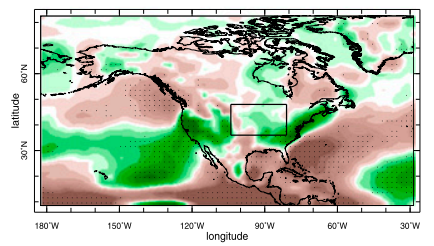

h1) Soil Moisture

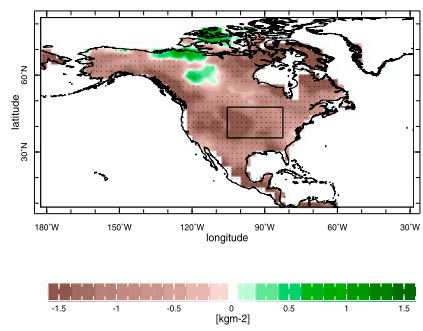

Change of CMIP5 Moisture Budget Terms for JJA

(US Corn Belt, 104W-81W, 37N-49N)

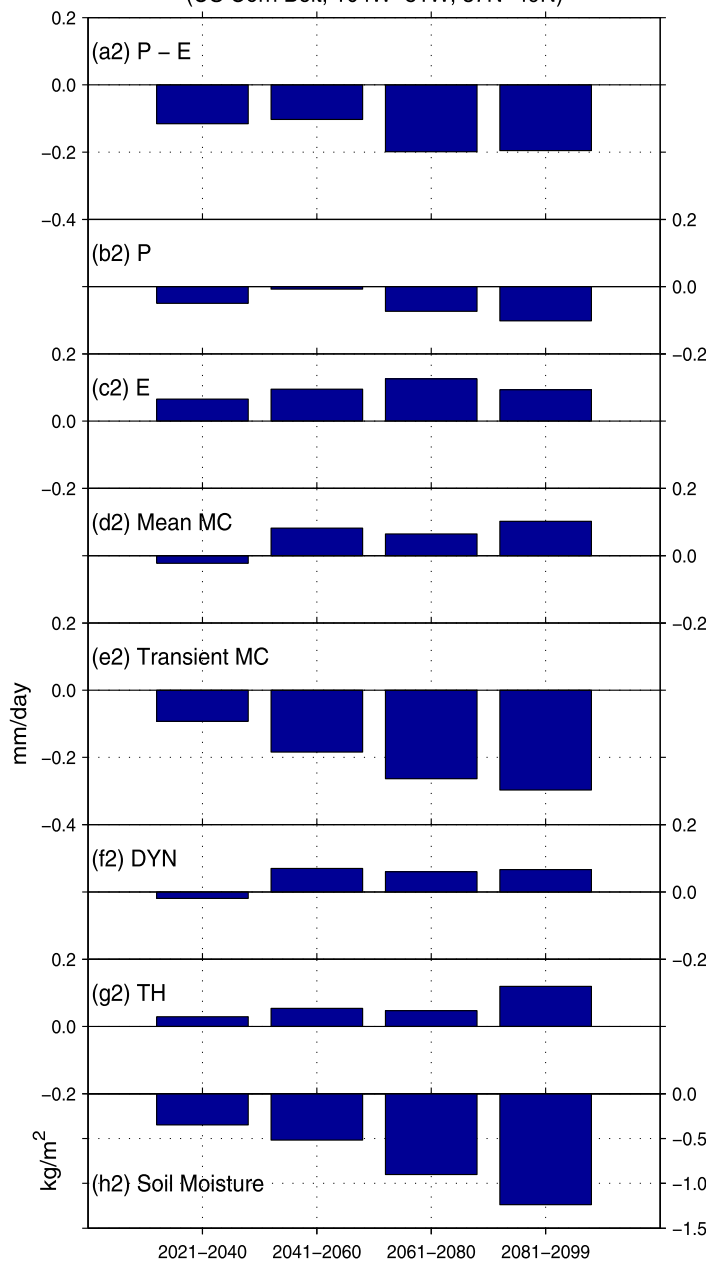

FIG. 4. Changes in JJA seasonal mean CMIP5 multimodel mean moisture budget terms between the end of the twenty-first century and the end of the twentieth century (2075-99 minus 1979-2005) for (a1) precipitation minus evapotranspiration; (b1) precipitation; (c1) evapotranspiration; (d1) mean moisture convergence; (e1) transient moisture convergence; changes in mean moisture convergence due to (f1) circulation and (g1) moisture; and (h1) top layer of the soil moisture. (a2)-(h2) Bar plots giving the corresponding changes of the moisture budget terms averaged over the corn-belt region (outlined box on the maps) for four different future periods: 2021-40, 2041-60, 2061-80, and 2081-99 relative to 1979-2005. Stippling in (a1)-(h1) indicates model agreement with 17 of 22 (77\%) models having the same sign changes.

the summer jet stream (Fig. 6a). This further leads to the reduction in storm activity over the corn-belt latitudes (Fig. 6b). The transient eddy heat flux (Fig. 6d) also reduces in magnitude as a result of the storm-track intensity change and the weakened zonal mean temperature gradient. However, the change in mean moisture gradient (Fig. 6e) paints a different picture from the temperature. As specific humidity is a nonlinear function of temperature (according to the ClausiusClapeyron relation), for a given temperature increase, moisture content increases more at warmer temperatures. The zonal mean moisture gradient actually increases in the future even as the temperature gradient decreases, particularly north of $40^{\circ} \mathrm{N}$. This increase in mean moisture gradient appears to be responsible for the increase in northward transient moisture fluxes (Fig. 6f) and the associated moisture divergence in the corn-belt region.
To explain the relationship between changes in transient eddy moisture fluxes and the mean moisture gradient, we can approximate the eddy moisture transport as (Green 1970; Wu et al. 2011)

$$
\overline{v^{\prime} q^{\prime}} \sim \overline{v^{\prime} L_{y}^{\prime} \frac{\partial \bar{q}}{\partial y}} \sim \overline{v^{\prime 2}} \frac{\partial \bar{q}}{\partial y} \tau,
$$

where $q$ and $v$ are specific humidity and meridional velocity, primes are departures from monthly means, and overbars indicate monthly mean; $L_{y}^{\prime}$ is the transient eddy meridional mixing length scale, and $\tau$ is the typical time scale of the transient eddy, so $L_{y}^{\prime}=v^{\prime} \tau$ and $q^{\prime} \sim L_{y}^{\prime}(\partial \bar{q} / \partial y)$. The change in the transient eddy moisture flux, $\overline{v^{\prime} q^{\prime}}$, can be written as

$$
\Delta\left(\overline{v^{\prime} q^{\prime}}\right) \sim \Delta\left(\overline{v^{\prime 2}} \frac{\partial \bar{q}}{\partial y} \tau\right)=\Delta\left(\overline{v^{\prime 2}}\right) \frac{\partial \bar{q}}{\partial y} \tau+\overline{v^{\prime 2}} \Delta\left(\frac{\partial \bar{q}}{\partial y}\right) \tau .
$$


a) $\bar{u}, 250 \mathrm{mb}$

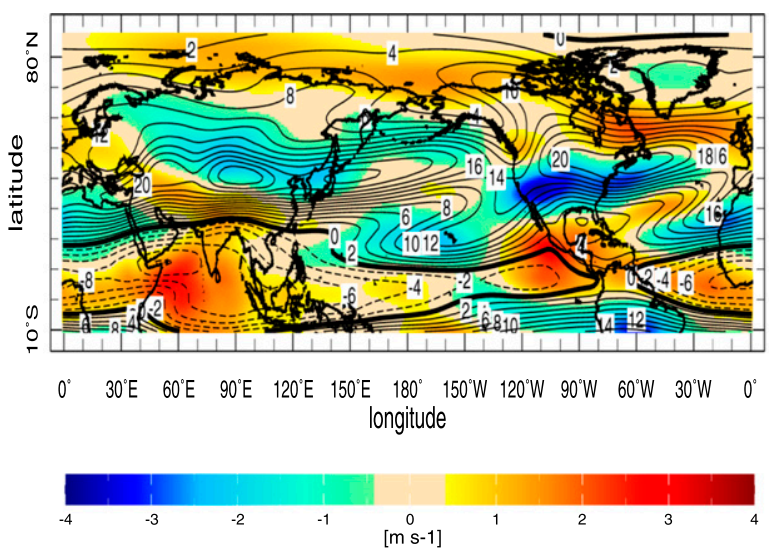

c) $\bar{u}, 700 \mathrm{mb}$
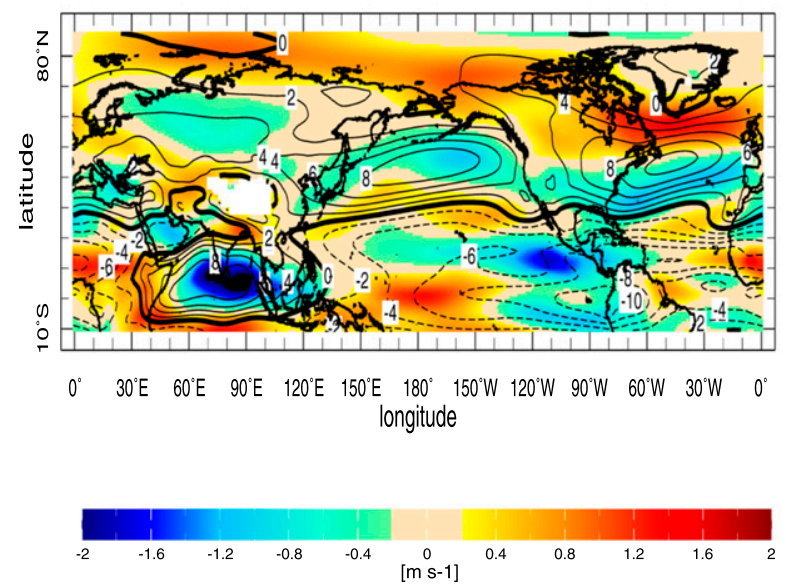

b) $\overline{u^{\prime 2}+v^{\prime 2}}, 250 \mathrm{mb}$
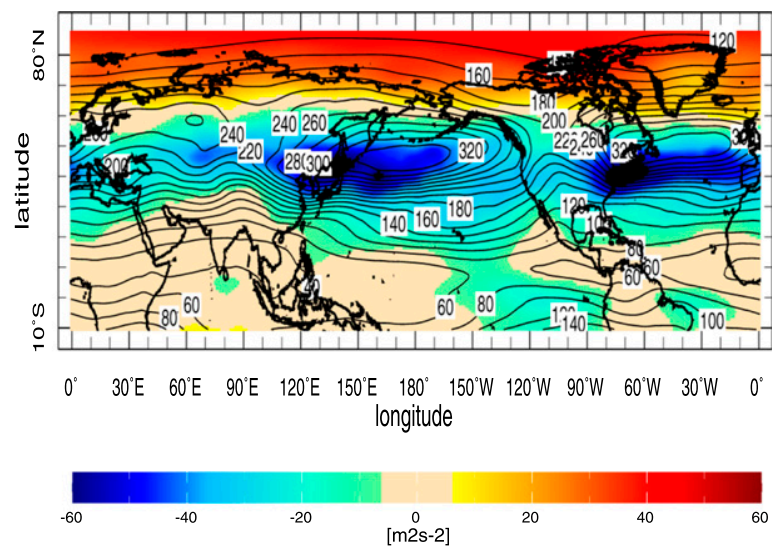

d) $\overline{u^{\prime 2}+v^{\prime 2}}, 700 \mathrm{mb}$

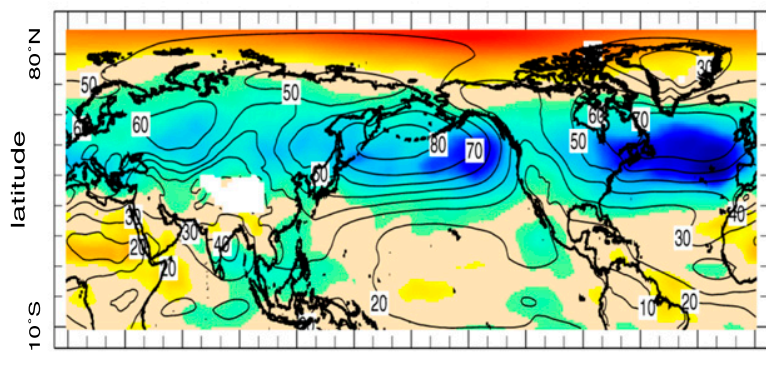
$\begin{array}{cccccccc}0^{\circ} & 30^{\circ} \mathrm{E} & 60^{\circ} \mathrm{E} & 90^{\circ} \mathrm{E} \quad 120^{\circ} \mathrm{E} \quad 150^{\circ} \mathrm{E} \quad 180^{\circ} \quad 150^{\circ} \mathrm{W} \quad 120^{\circ} \mathrm{W} & 90^{\circ} \mathrm{W} & 60^{\circ} \mathrm{W} & 30^{\circ} \mathrm{W} & 0^{\circ} \\ \text { longitude }\end{array}$

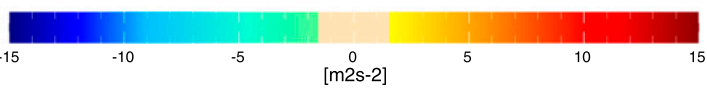

FIG. 5. JJA climatological mean (1975-2005) (contours) and changes between 2075-2100 and 1979-2005 (shading) in (a),(c) zonal wind and (b),(d) submonthly transient eddy kinetic energy at (top) 250 and (bottom) $700 \mathrm{hPa}$. The data are taken from CMIP5 MMM.

To determine if there is a change in the transient eddy time scale $\tau$ in Eq. (7) between future periods and the base period, we performed a power spectrum analysis of the 6-hourly meridional wind averaged over the corn-belt region in selected models. The results indicate no substantial change in time scales (figure not shown), so we can assume the time scale $\tau$ remains the same for the future periods. Thus Eq. (7) states that the change in transient moisture flux is determined by the change in storm activity $\left(\overline{v^{\prime 2}}\right)$ and the change in mean moisture gradient $(\partial \bar{q} / \partial y)$. Figure 6 demonstrate that the increase in mean moisture gradient [second term in Eq. (7)] dominates over the reduction in storm activity [first term in Eq. (7)], which leads to the increase in northward moisture flux north of $40^{\circ} \mathrm{N}$ (Fig. 6f). For heat flux shown in Fig. 6d, both the mean temperature gradient and the storm activity reduce, and thus the northward heat flux also decreases.

We can apply the above understanding of the transient moisture flux to explain why the corn-belt region is particularly susceptible to summer drying. From the Great Plains lowlevel jet (GPLLJ), there is strong moisture transport from the south toward the U.S. southern plains leading to a local maximum in specific humidity (Fig. 7a). In the future, even when circulation changes are relatively small, the increased temperature in the tropics creates a stronger north-south moisture gradient as shown in Fig. 6e, which then leads to a stronger local specific humidity tongue in the central United States driven by the mean moisture advection (Fig. 7b). This further leads to a local maximum in specific humidity change in the U.S. central plains (Fig. 7c). Transient eddies tend to transport moisture northward to diffuse the climatological moisture gradient as shown in Fig. $7 d$. In the future, the local mean moisture maximum in Fig. $7 \mathrm{c}$ leads to anomalous moisture flux both northward and southward (or decreased northward transport of moisture at the southern boundary and increased northward transport at the northern boundary), causing anomalous moisture 
a) Zonal Wind $\left(m s^{-1}\right)$

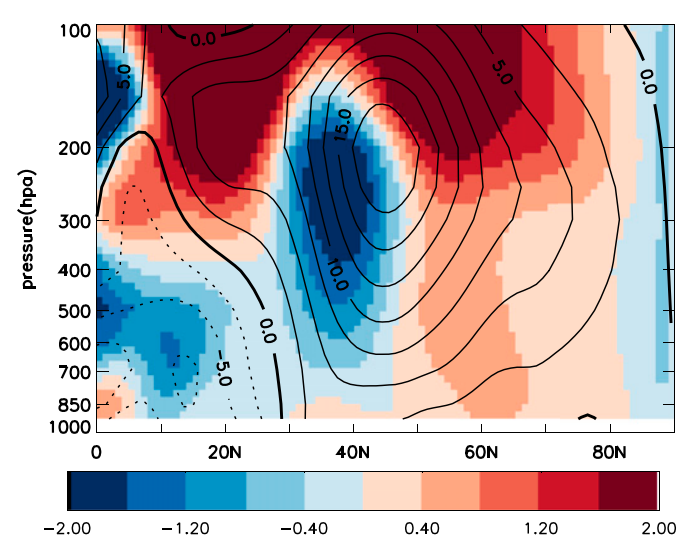

c) Temperature (Deg C)

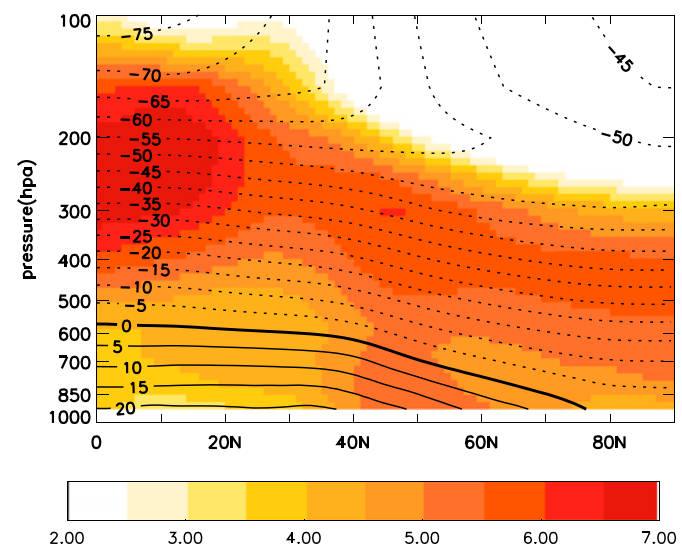

e) Specific Humidity $\left(g k g^{-1}\right)$

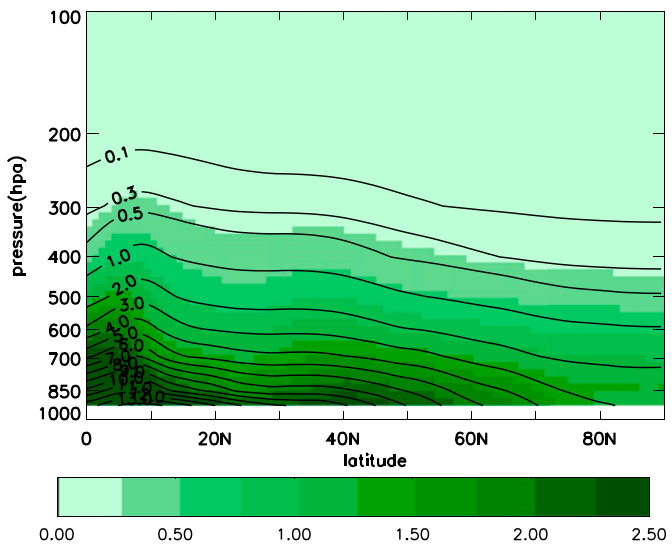

b) $\overline{v^{\prime 2}}$

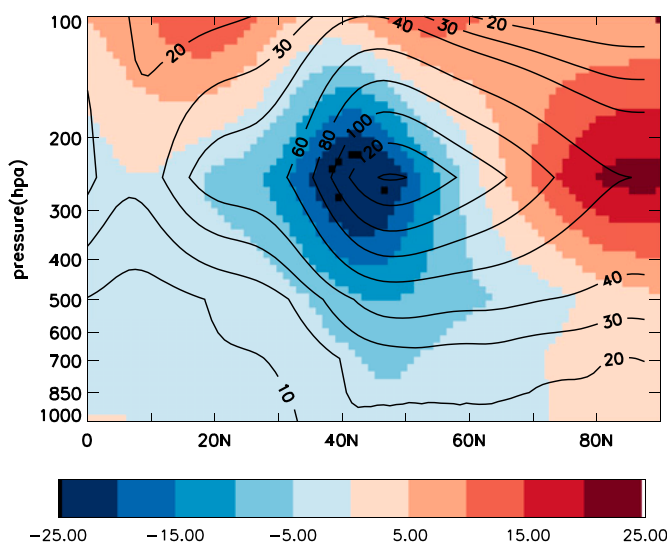

d) $\overline{v^{\prime} T^{\prime}},\left(m s^{-1} K\right)$

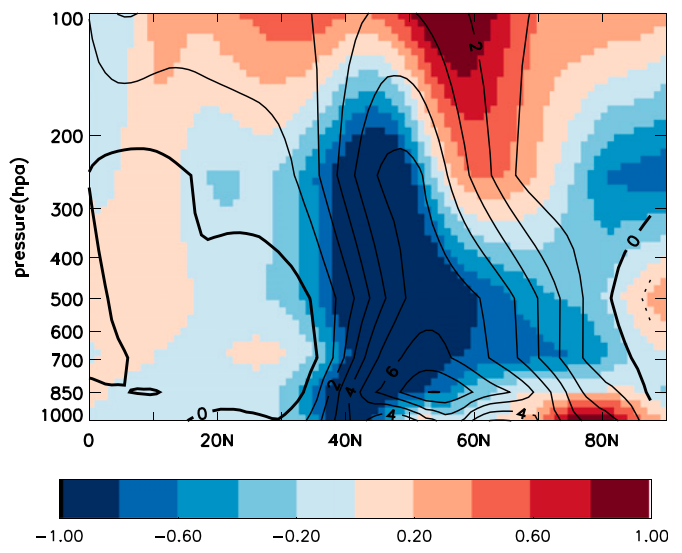

f) $\overline{v^{\prime} q^{\prime}},\left(m s^{-1} g k g-1\right)$

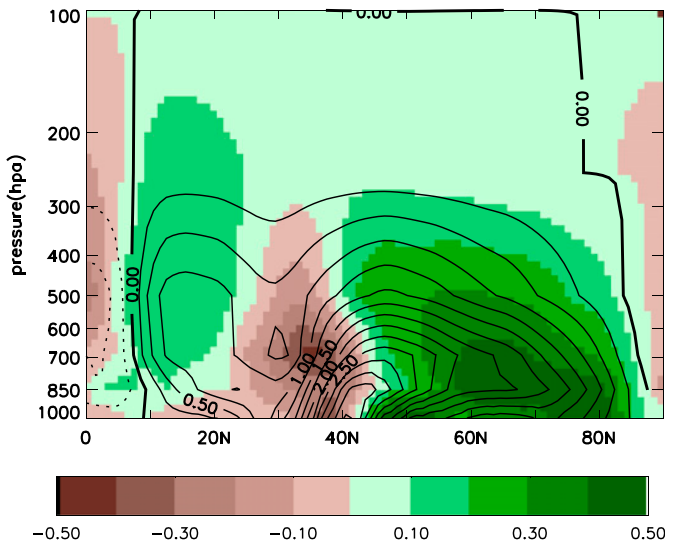

FIG. 6. JJA climatology (contours) and changes between 2075-99 and 1979-2005 (shading) in CMIP5 multimodel zonally averaged for North American longitudes $\left(130^{\circ}-50^{\circ} \mathrm{W}\right)$ for (a) zonal wind, (b) submonthly transient eddy meridional wind variance, (c) temperature, (d) transient heat fluxes, (e) specific humidity, and (f) transient eddy moisture fluxes.

divergence in the U.S. corn-belt region (Fig. 7e). This mechanism is very similar to the regional zonal mean transient moisture flux shown in Fig. 6f, in the sense that even though transient eddies weakened in the future, the moisture fluxes actually intensified by the enhanced mean moisture gradient. This mechanism tends to be particularly strong in the corn-belt region due to the anomalous local moisture gradient caused by the GPLLJ as shown in 
$\overline{\mathbf{v}}\left(m s^{-1}\right)$, Contours-SLP(hpa), Shading-VI600q

a) $1979-2005$

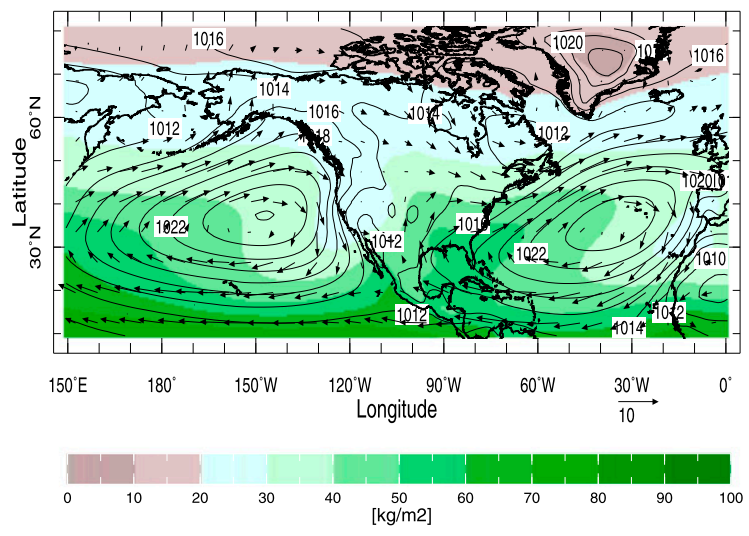

b) 2075-2099

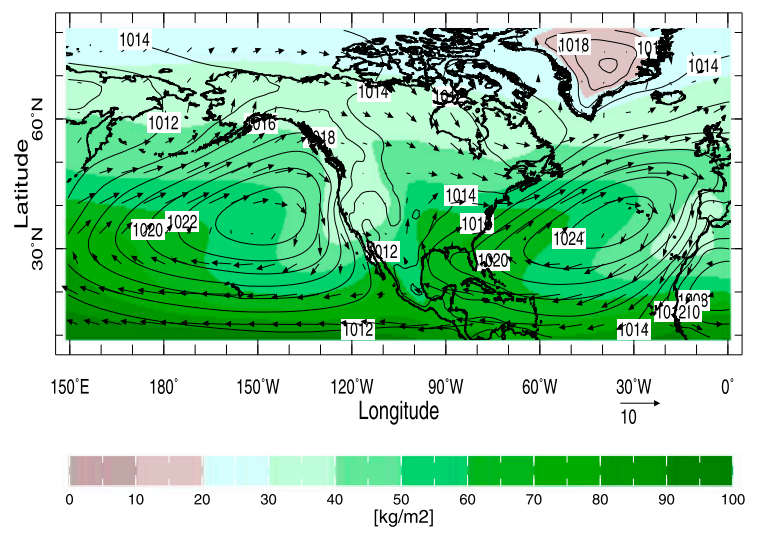

c) (2075-2099)-(1979-2005)

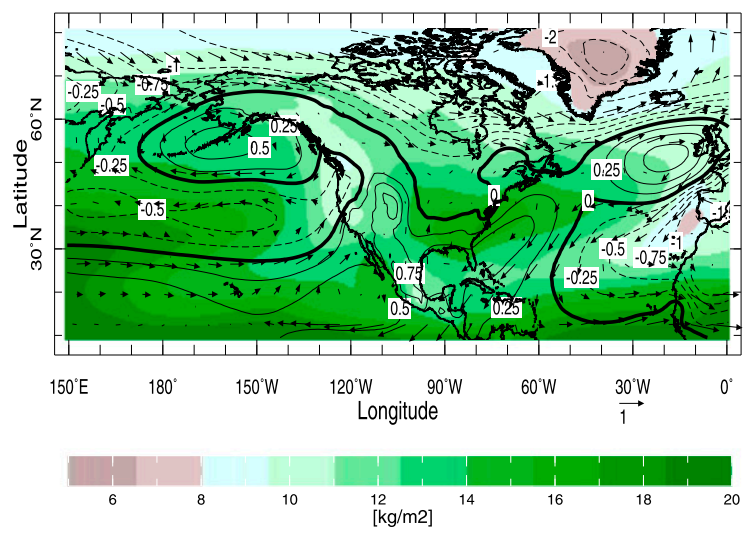

Figs. 7a-c. In summary, the soil drying in the U.S. corn-belt region is largely caused by the increased evapotranspiration, which supplies more moisture into the atmosphere. Because of the reduced storm activity, however, precipitation is also reduced in the region. The moisture gained by the atmosphere that is due to reduced $P-E$ and enhanced

\section{$\overline{\mathbf{v}^{\prime} q^{\prime}}\left(m s^{-1} g k g^{-1}\right)$, Shading-Transient MC}

d) $1979-2005$

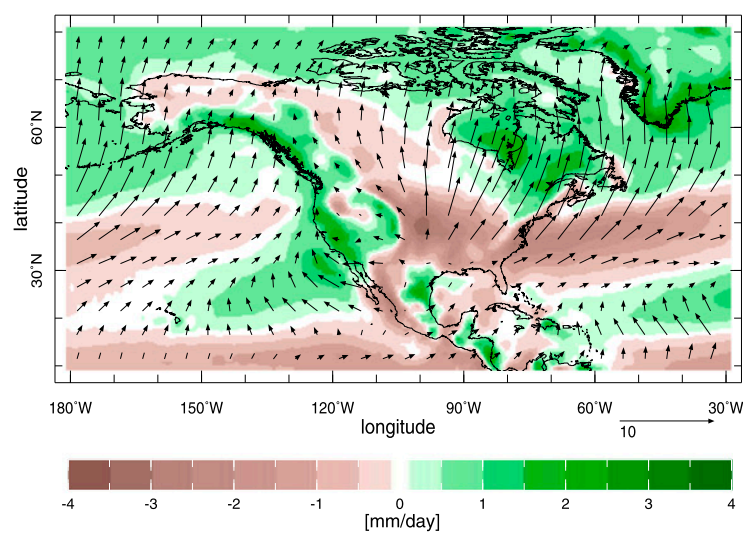

e) (2075-2099)-(1979-2005)

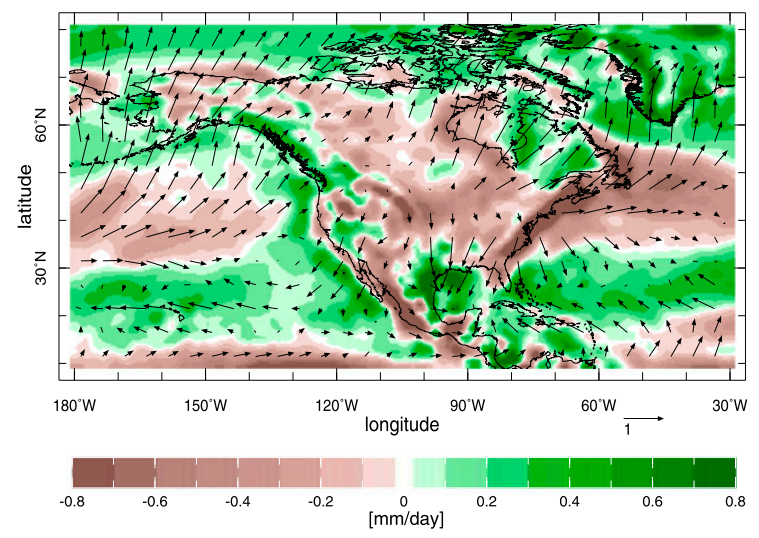

FIG. 7. JJA sea level pressure (contours),vertically integrated specific humidity from the surface to $600 \mathrm{hPa}$ (shading), and $850-\mathrm{hPa}$ wind vectors averaged for (a) 1979-2005, (b) 2075-99, and (c) 2075-99 minus 1979-2005, and submonthly transient moisture fluxes at $700 \mathrm{hPa}$ averaged for (d) 1979-2005 and (e) 2075-99 minus 1979-2005. All data are from CMIP5 MMM. mean flow moisture convergence is then transported out of the region by transient eddies.

\section{Summary and conclusions}

The future changes in corn-belt precipitation, evapotranspiration, moisture transports, and storm activity are summarized 
in Fig. 8b. When future storm-track activity decreases as a result of the weakened north-south temperature gradient in the lower troposphere, it exerts two distinct impacts on local moisture budget. On the one hand, the reduction in storm activity reduces the amount of precipitation associated with summer storm tracks. At the same time, and in response to strengthened meridional moisture gradients, transient eddies act diffusively to remove more moisture out of the corn-belt region. Together these processes cause drying in the region in terms of a negative $P-E$ perturbation and soil moisture drying. Due to warming and $\mathrm{CO}_{2}$-induced greening (Mankin et al. 2017), there is also a tendency to increase evapotranspiration. This can further exacerbate the surface soil drying as the transient eddies diverge away the gained atmospheric moisture. The ultimate cause of the drying in the corn-belt region arises from the fact that the reduced north-south temperature gradient and the weakened storm activity associated with it are overwhelmed by the effect of the enhanced north-south humidity gradient. As long as models are simulating these effects correctly, the summer drying in the corn-belt region should be a robust feature of future climate change.

Previous studies have argued that the drying may be caused by model bias in simulating the climatology. However, our results argue that the future drying in this region is physically based and easily related to the processes controlling the climatological moisture budget in both models and reanalysis. Whatever causes the model dry bias in the climatology should not necessarily translate to a future dry bias. At the same time, the future drying mechanism stems from a robust feature of the greenhouse warming and should be taken seriously in future planning for the corn-belt region. These results add to understanding of the "greening but drying" response to increasing $\mathrm{CO}_{2}$ identified by Mankin et al. (2019). They demonstrated that, despite gains in the water use efficiency of photosynthesis, models project higher evapotranspiration over much of continental North America. The increased moisture flux to the atmosphere is allowed because of the increased transient eddy moisture divergence. Mankin et al. (2019) found a similar higher evapotranspiration over Eurasia where we suspect the same physical processes operate, but this needs to be examined further.

We also explored if such change had already begun in the observed data. Unfortunately the internal variability in stormtrack intensity makes it difficult to detect such a change, along with problems with estimating trends in reanalysis products. When this drying signal may become detectable in single realizations, such as the observed state, is a question that should be further explored in the future using large ensemble simulations that are based on single or multiple models.

Acknowledgments. This research was supported by National Oceanic and Atmospheric Administration Grants NA17OAR4310126 and NA20OAR4310379, and National Science Foundation Grant AGS-1934358. We acknowledge Ms. Chunyu Liu for her help with making Fig. 1 in the paper. We appreciate the constructive comments provided by Drs. Paul Dirmeyer and Qiang Fu and an anonymous reviewer on earlier versions of the paper, which improved the clarity of

\section{(a) Summer Climatological Moisture Budget} Process:

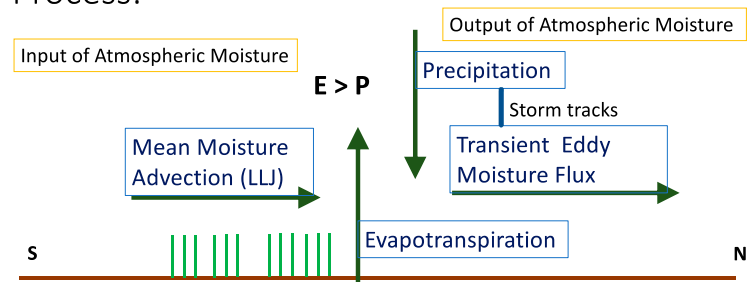

(b) Future Changes in the U.S. Corn Belt Summer Moisture Budget Process:

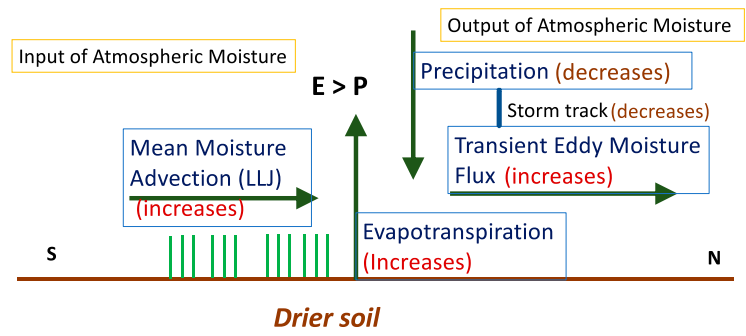

FIG. 8. Schematic illustration of (a) summer mean moisture budget processes (sources and sinks) and (b) future changes under global warming scenarios for the U.S. corn-belt region. The darkgreen arrows indicate directions of moisture fluxes, the blue arrow indicates the link between storm track and precipitation, and the light-green vertical lines represent surface vegetation. For the summer climatology in (a), mean moisture advection supplies moisture to the region along with evapotranspiration while transient eddies remove water vapor through precipitation and transport out of the region by diffusive processes. In the future in (b), mean moisture advection increases as a result of increased moisture in the atmosphere and an enhanced moisture gradient between the tropics and midlatitudes. Evapotranspiration also increases under the influence of atmospheric warming. However, storm-track activity decreases because of a reduced north-south temperature gradient and precipitation reduces. Nonetheless, transient eddies transport more moisture out of the region diffusively because of an enhanced north-south humidity gradient. Therefore, the increased transient eddy moisture divergence sustains the surface drying.

the results. We thank Dr. Justin Mankin for helpful discussions about biogeochemical processes in CMIP5 models and $\mathrm{CO}_{2}$ fertilization and its impacts on water use efficiency.

Data availability statement.. Both the observational and CMIP model outputs used in this study are freely available from the following sites: the ERA-Interim monthly data (https://www.ecmwf.int/en/forecasts/datasets/reanalysis-datasets/ era-interim), CMIP5 model outputs (https://pcmdi.llnl.gov/mips/ cmip5/data-portal.html), and the gridded precipitation data from the GPCC (https://psl.noaa.gov/data/gridded/data.gpcc.html) and CRU (https://crudata.uea.ac.uk/cru/data/hrg/). The CMIP5 moisture budget analysis can be accessed online (http:// kage.ldeo.columbia.edu:81/SOURCES/.LDEO/.ClimateGroup/ .PROJECTS/.IPCC/.CMIP5/.MoistureBudget/.mmm_22models_ v3/.historical/ and http://kage.ldeo.columbia.edu:81/SOURCES/ 
.LDEO/.ClimateGroup/.PROJECTS/.IPCC.CMIP5/.MoistureBudget/ .mmm_22models_v3/.rcp85/). The ERA-I moisture budget analysis can also be accessed online (http://kage.ldeo.columbia.edu: 81/OTHER/.MoistureBudgets/.ERAInterim/.VertInt_26/).

\section{REFERENCES}

Cook, B., T. R. Ault, and J. E. Smerdon, 2015: Unprecedented 21st century drought risk in the American Southwest and Central Plains. Sci. Adv., 1, e1400082, https://doi.org/10.1126/ sciadv.1400082.

Dee, D. P., and Coauthors, 2011: The ERA-Interim reanalysis: Configuration and performance of the data assimilation system. Quart. J. Roy. Meteor. Soc., 137, 553-597, https://doi.org/ 10.1002/qj.828.

Dirmeyer, P. A., and K. L. Brubaker, 2006: Evidence for trends in the Northern Hemisphere water cycle. Geophys. Res. Lett., 33, L14712, https://doi.org/10.1029/2006GL026359.

Fu, Q., and S. Feng, 2014: Responses of terrestrial aridity to global warming. J. Geophys. Res. Atmos., 119, 7863-7875, https:// doi.org/10.1002/2014JD021608.

—, C. M. Johanson, J. M. Wallace, and T. Reichler, 2006: Enhanced mid-latitude tropospheric warming in satellite measurements. Science, 312, 1179, https://doi.org/10.1126/ science. 1125566.

Green, J. S. A., 1970: Transfer properties of the large-scale eddies and the general circulation of the atmosphere. Quart. J. Roy. Meteor. Soc., 96, 157-185, https://doi.org/10.1002/ qj. 49709640802.

Green, T. R., H. Kipka, O. David, and G. S. McMaster, 2018: Where is the USA corn belt, and how is it changing? Sci. Total Environ., 618, 1613-1618, https://doi.org/10.1016/ j.scitotenv.2017.09.325.

Harris, I., T. J. Osborn, P. Jones, and D. Lister, 2020: Version 4 of the CRU TS monthly high-resolution gridded multivariate climate dataset. Sci. Data, 7, 109, https://doi.org/10.1038/ s41597-020-0453-3.

Klein, S. A., X. Jiang, J. Boyle, S. Malyshev, and S. Xie, 2006: Diagnosis of the summertime warm and dry bias over the U.S. Southern Great Plains in the GFDL climate model using a weather forecasting approach. Geophys. Res. Lett., 33, L18805, https://doi.org/10.1029/2006GL027567.

Lemordant, L., P. Gentinea, A. S. Swann, B. I. Cook, and J. Scheff, 2018: Critical impact of vegetation physiology on the continental hydrologic cycle in response to increasing $\mathrm{CO}_{2}$. Proc. Natl. Acad. Sci. USA, 115, 4093-4098, https://doi.org/10.1073/ pnas.1720712115.

Lin, Y., W. Dong, M. Zhang, Y. Xie, W. Xue, J. Huang, and Y. Luo, 2017: Causes of model dry and warm bias over central U.S. and impact on climate projections. Nat. Commun., 8, 881, https:// doi.org/10.1038/s41467-017-01040-2.

Maloney, E. D., and Coauthors, 2014: North American climate in CMIP5 experiments. Part III: Assessment of twenty-firstcentury projections. J. Climate, 27, 2230-2270, https://doi.org/ 10.1175/JCLI-D-13-00273.1.

Manabe, S., R. T. Wetheraid, and R. J. Stouffer, 1981: Summer dryness due to an increase of atmospheric $\mathrm{CO}_{2}$ concentration. Climatic Change, 3, 347-386, https://doi.org/10.1007/ BF02423242.

Mankin, J. S., J. E. Smerdon, B. I. Cook, A. P. Williams, and R. Seager, 2017: The curious case of projected twenty-firstcentury drying but greening in the American West. J. Climate, 30, 8689-8710, https://doi.org/10.1175/JCLI-D-17-0213.1.
—, R. Seager, J. E. Smerdon, B. I. Cook, A. P. Williams, and R. M. Horton, 2018: Blue water trade-offs with vegetation in a $\mathrm{CO}_{2}$-enriched climate. Geophys. Res. Lett., 45, 3115-3125, https://doi.org/10.1002/2018GL077051.

,,,,---- and P. Williams, 2019: Mid-latitude freshwater availability reduced by projected vegetation responses to climate change. Nat. Geosci., 12, 983-988, https://doi.org/ 10.1038/s41561-019-0480-x.

Milly, P., and K. Dunne, 2016: Potential evapotranspiration and continental drying. Nat. Climate Change, 6, 946-949, https:// doi.org/10.1038/nclimate3046.

Mueller, B., and S. I. Seneviratne, 2014: Systematic land climate and evapotranspiration biases in CMIP5 simulations. Geophys. Res. Lett., 41, 128-134, https://doi.org/ 10.1002/2013GL058055.

Rind, D., 1988: The doubled $\mathrm{CO}_{2}$ climate and the sensitivity of the modeled hydrologic cycle. J. Geophys. Res., 93, 5385-5412, https://doi.org/10.1029/JD093iD05p05385.

Santer, B. D., and Coauthors, 2018: Human influence on the seasonal cycle of tropospheric temperature. Science, 361, eaas 8806 , https://doi.org/10.1126/science.aas8806.

Schneider, U., A. Becker, P. Finger, A. Meyer-Christoffer, M. Ziese, and B. Rudolf, 2014: GPCC's new land surface precipitation climatology based on quality-controlled in situ data and its role in quantifying the global water cycle. Theor. Appl. Climatol., 115, 15-40, https://doi.org/10.1007/s00704013-0860-x.

Seager, R., and N. Henderson, 2013: Diagnostic computation of moisture budgets in the ERA-Interim reanalysis with reference to analysis of CMIP-archived atmospheric model data. J. Climate, 26, 7876-7901, https://doi.org/10.1175/JCLI-D-1300018.1.

—, D. Neelin, I. Simpson, H. Liu, N. Henderson, T. Shaw, Y. Kushnir, and M. Ting, 2014: Dynamical and thermodynamical causes of large-scale changes in the hydrological cycle over North America in response to global warming. J. Climate, 27, 7921-7948, https://doi.org/10.1175/JCLI-D14-00153.1.

_ J. Feldman, N. Lis, M. Ting, A. P. Williams, J. Nakamura, H. Liu, and N. Henderson, 2018: Whither the 100th meridian? The once and future physical and human geography of America's arid-humid divide: Part II: The meridian moves east. Earth Interact., 22, https://doi.org/10.1175/EI-D-170012.1.

Sheffield, J. and Coauthors, 2013: North American climate in CMIP5 experiments. Part I: Evaluation of historical simulations of continental and regional climatology. J. Climate, 26, 9209-9245, https://doi.org/10.1175/JCLI-D-12-00592.1.

Sherwood, S., and Q. Fu, 2014: A dryer future? Science, 343, 737-739, https://doi.org/10.1126/science.1247620.

Swann, A., F. M. Hoffman, C. D. Koven, and J. T. Randerson, 2016: Plant responses to increasing $\mathrm{CO}_{2}$ reduce estimates of climate impacts on drought severity. Proc. Natl. Acad. Sci. USA, 113, 10 019-10 024, https://doi.org/10.1073/ pnas. 1604581113.

Ting, M., and H. Wang, 2006: The role of the North American topography on the maintenance of the Great Plains summer low-level jet. J. Atmos. Sci., 63, 1056-1068, https://doi.org/ 10.1175/JAS3664.1.

, R. Seager, C. Li, and H. Liu, 2018: Mechanism of future spring drying in the southwest United States in CMIP5 models. J. Climate, 31, 4265-4279, https://doi.org/10.1175/ JCLI-D-17-0574.1. 
USDA-NASS, 2018: Agricultural Statistics 2018. USDA National Agricultural Statistics Service Doc., 502 pp., https://downloads.usda.library.cornell.edu/usda-esmis/files/ j3860694x/2z10wz00c/9019s972q/Ag_Stats_2018.pdf.

Weaver, S. J., and S. Nigam, 2008: Variability of the Great Plains low-level jet: Large-scale circulation context and hydroclimate impacts. J. Climate, 21, 1532-1551, https://doi.org/10.1175/ 2007JCLI1586.1.
Wilson, C. A., and J. F. B. Mitchell, 1987: A doubled climate sensitivity experiment with a global climate model including a simple ocean. J. Geophys. Res., 92, 13 315-13 343, https:// doi.org/10.1029/JD092iD11p13315.

Wu, Y., M. Ting, R. Seager, H.-P. Huang, and M. A. Cane, 2011: Changes in storm tracks and energy transports in a warmer climate simulated by the GFDL CM2.1 model. Climate Dyn., 37, 53-72, https://doi.org/10.1007/s00382-010-0776-4. 